\title{
Pengaruh Gaya Kepemimpinan Dan Kompensasi Terhadap Kepuasan Kerja
} Karyawan PT. Citra Rasa Betawi

\author{
${ }^{1}$ Muhamad Abid, ${ }^{2}$ Dede Andi \\ Dosen Fakultas Ekonomi Universitas Pamulang \\ Email : 1 dosen02466@unpam.ac.id, 201osen02463@unpam.ac.id
}

\begin{abstract}
ABSTRAK
Tujuan dari penelitian ini adalah untuk mengentahui gaya kepemimpinan, kompensasi dan pengaruhnya terhadap kepuasan kerja karyawan di PT. Citra Rasa Betawi.

Metode penelitian yang digunakan penulis adalah metode asosiatif, sedangkan metode pengolahan data bersifat kuantitatif, metode penentuan sample menggunakan rumus slovin dari 500 populasi yang ada menjadi 222 responden, metode pengumpulan data menggunakan penyebaran kuesioner (angket) dan metode analisi data menggunakan uji validitas, uji reabilitas, uji koefisien korelasi product moment, uji koefisien determinasi atau koefisien penentu, dan uji hipotis dan operasional variabel peneliti menggunakan variabel bebas (variable indevenden) yaitu pelatihan kerja dan variabel terikat (variable devendent) yaitu kinerja karyawan.

Berdasarkan hasil penelitian dengan taraf signifikansi 5\% diperoleh kesimpulan: (1) Terdapat pengaruh posistif dan signifikan secara parsial antara Gaya Kepemimpinan (X1) terhadap Kepuasan Kerja Karyawan (Y). ditunjukan dengan nilai thitung $15.812>$ ttabel 1.971. atau Sig $0.000<0.05$, Tingkat hubungan sebesar 0.532 artinya tingkat hubungan yang kuat.(2) Terdapat pengaruh posistif dan signifikan secara parsial antara Kompensasi (X2) terhadap Kepuasan Kerja Karyawan (Y). ditunjukan dengan nilai thitung 18.807 > ttabel 1.971. atau Sig 0.000 $<0.05$. Tingkat hubungan sebesar 0.617 artinya tingkat hubungan yang kuat. (3) Terdapat pengaruh secara simultan antara Gaya Kepemimpinan (X1) Kompensasi (X2) terhadap Kepuasan Kerja Karyawan (Y). ditunjukan dengan nilai Fhitung $260.344>$ Ftabel 3.04, dan Sig. 0,000 lebih kecil dari alpha 5\% (0.05). hasil regresi linear berganda $\hat{\mathrm{Y}}=16.318+0.287 \mathrm{X} 1+0.506 \mathrm{X} 2$ dimana konstanta sebesar 16.318. Nilai Adjustes R Square sebesar 0.573 yang menunjukan bahwa variable Kepuasan Kerja Karyawan (Y) dipengaruhi oleh variable Gaya Kepemimpinan (X1) dan variable Kompensasi (X2) sebesar 70,4\% dan sisanya sebesar 29,6\% dipengaruhi oleh variable lain yang tidak diteliti.
\end{abstract}

\section{Kata Kunci : Gaya Kepemimpinan, Kompensasi, dan Kepuasan Kerja}




\section{PENDAHULUAN}

\section{Latar Belakang Masalah}

PT Citra Rasa Betawi adalah perusahaan keluarga yang usahanya bergerak dibidang restoran makanan tradisional, perusahaan ini berdiri dari tahun 1992 sampai dengan saat ini karyawannya kurang lebih 500 karyawan. Berdasarkan observasi pra penelitian di PT Citra Rasa Betawi ditemukan permasalahan yang perlu diperhatikan oleh perusahaan terkait kepuasan kerja karyawan.

Permasalahan yang muncul adalah banyaknya ketidak pastian manajemen yang membuat karyawan merasa bingung, tidak adanya tujuan yang jelas, target yang spesifik sehingga karyawan kesulitan merealisasikan apa yang menjadi mimpi perusahaan, tidak adanya management review untuk performance perusahaan maupun performance karyawan, sehingga karyawan merasa tidak puas dengan hasil kerjanya karena tidak pernah berprestasi dan kurangnya penghargaan kepada karyawan, tidak adanya system insentive ataupun bonus baik bulanan maupun tahunan bagi karyawan, begitu juga dengan gaji karyawan disaat UMR (Upah Minimum Regional) DKI Jakarta tahun 2019 sebesar Rp 3.940.973 beberapa jabatan gajinya masih di bawah UMR.

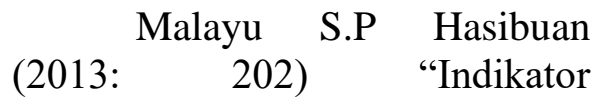
kepuasankerja hanya dapat diukur dengan kedisiplinan, tingkat kedisiplinan karyawandapat dilihat dari absensi kehadiran karyawan dalam bekerja". Kedisiplinan karyawan merupakan masalah selanjutnya pada PT. Citra Rasa Betawi sedangkan kedisiplinan karyawan sangat penting bagi perusahaan, sehingga pimpinan perlu memperhatikan karyawan agar dapat meminimalisir ketidakhadiran karyawan. Kondisi ini tentunya dapat menghambat pencapaian kinerja perusahaan secara keseluruhan termasuk upaya dalam meningkatkan kinerja karyawannya.

Menurut Handoko dalam Edy Sutrisno (2016:75) “Kepuasan kerja adalah keadaan emosional yang menyenangkan atau tidak menyenangkan bagi para karyawan memandang pada pekerjaan mereka. Kepuasan kerja mencerminkan perasaan seseorang terhadap pekerjaanya. Perasaan menyenangkan atau tidak menyenangkan biasanya berdasarkan respon atau sikap atasan pada saat karyawan melakukan pekerjaan, disaat pimpinan melihat dan mengakui hasil pekerjaan sikaryawan maka karyawan akan merasa senang dan mempunyai dorongan untuk bekerja lebih baik lagi, namun sebaliknya apabila karyawan sudah merasa bekerja maksimal namun tidak dilihat maka kepuasan kerja karyawan akan menurun.

Kompensasi menurut Malayu S.P Hasibuan (2013) adalah semua pendapatan yang berbentuk uang, barang langsung atau tidak langsung yang diterima karyawan sebagai imbalan atas jasa yang diberikan kepada perusahaan. Pemberian kompensasi yang tepat akan 
berpengaruh positif terhadap kepuasan kerja dan kinerja karyawan. Adanya kompensasi berupa bonus, hadiah maupun penghargaan juga akan memberikan dampak yang positif bagi karyawan. Karyawan akan merasa termotivasi dan bersemangat dalam menyelesaikan tugas yang diberikan serta akan muncul dorongan karyawan untuk berprestasi.

Oleh karena beberapa identifikasi masalah diatas penulis memutuskan untuk melakukan pengkajian yang lebih mendalam kepada perusahan dengan jdul penelitian PENGARUH GAYA KEPEMIMPINAN DAN KOMPENSASI TERHADAP KEPUASAN KERJA KARYAWAN.

\section{Rumusan Masalah}

a. Seberapa besar pengaruh gaya kepemimpinan terhadap kepuasan kerja karyawan PT Citra Rasa Betawi ?

b. Seberapa besar pengaruh kompensasi terhadap kepuasan kerja karyawan PT Citra Rasa Betawi ?

c. Seberapa besar pengaruh gaya kepemimpinan dan kompensasi terhadap kepuasan kerja karyawan PT Citra Rasa Betawi ?

\section{Tujuan Penelitian}

a. Untuk mengetahui seberapa besar pengaruh gaya kepemimpinan terhadap kepuasan kerja karyawan PT Citra Rasa Betawi?

b. Untuk mengetahui seberapa besar pengaruh kompensasi terhadap kepuasan kerja karyawan PT Citra Rasa Betawi?

c. Untuk mengetahui seberapa besar pengaruh gaya kepemimpinan dan kompensasi terhadap kepuasan kerja karyawan PT Citra Rasa Betawi?

\section{TINJAUAN PUSTAKA}

\section{Gaya Kepemimpinan}

Tampubolon

(2007)

menjelaskan bahwa gaya kepemimpinan adalah perilaku dan strategi, sebagai hasil kombinasi dari falsafah, keterampilan, sifat, sikap, yang sering diterapkan seorang pemimpin ketika ia mencoba mempengaruhi kinerja bawahannya.

\section{Kompensasi}

Notoatmodjo menyatakan bahwa kompensasi adalah segala sesuatu yang diterima oleh karyawan sebagai balas jasa untuk kerja atau pengabdian mereka. Faktor-faktor yang mempengaruhi kompensasi adalah produktivitas, kemampuan untuk membayar, kesediaan untuk membayar, suplai dan permintaan tenaga kerja, organisasi karyawan dan peraturan dan perundangundangan.

Penulis berpendapat bahwa kompensasi merupakan segala sesuatu yang diterima karyawan baik secara langsung maupun tidak langsung baik berupa pendapatan secara materi atau non meteri sebagai imbal jasa atas kontribusi, kerja, pengabdian terhadap perusahaan atau organisasi.

\section{Kepuasan Kerja} Menurut Mangkunegara 
(2011: 117) kepuasan kerja adalah suatu perasaan yang menyokong atau tidak menyokong diri pegawai yang berhubungan dengan pekerjaannya maupun dengan kondisi dirinya, Sedangkan Handoko (2002: 193) menyatakan bahwa kepuasan kerja (job satisfaction) adalah keadaan emosional yang menyenangkan atau tidak menyenangkan dengan mana karyawan memandang pekerjaan mereka.

Dole dan Schroeder (2001) dalam Koesmono (2005: 170) menjelaskan bahwa kepuasan kerja dapat didefinisikan sebagai perasaan dan reaksi individu terhadap lingkungan pekerjaannya.

\section{METODE PENELITIAN}

\section{Populasi}

populasi yang diambil oleh penulis di PT. Citra Rasa Betawi adalah sebanyak 500 karyawan diseluruh Jabodetabek.

\section{Sampel}

Teknik pengambilan sampling dalam penelitian ini adalah menggunakan rumus slovin (Umar Husain, 2004: 49), dengan tingkat eror yang ditoleransi sebanyak 5\%, berdasarkan perhitungan rumus tersebut didapatkan sampel sebanyak 222 karyawan.

\section{Jenis Penelitian}

Jenis penelitian yang dipakai adalah penelitian asosiatif kuantitatif. Menurut Sugiyono (2016:36) penelitian asosiatif merupakan penelitian yang bertujuan untuk mengetahui pengaruh ataupun hubungan antara dua variabel atau lebih. Peneliti menggunakan metode penelitian asosiatif dengan pendekatan kuantitatif.

\section{Metode Analisis Data}

Dalam menganalisis data digunakan uji validasi, uji reliabilitas, uji normalitas, uji asumsi klasik dan uji hipotesis.

\section{HASIL PENELITIAN}

\section{Analisis Deskriptif}

Pada pengujian ini digunakan untuk mengetahui besarnya persentase minimum dan maksimum, persentase rata-rata dan standar deviasi dari masingmasing variabel. Adapun hasilnya sebagai berikut:

Tabel 1. Hasil Analisis Descriptive Statistics Descriptive Statistics

\begin{tabular}{lc|c|c|c|c} 
& $\mathrm{N}$ & Minimum & Maximum & Mean & Std. Deviation \\
\hline $\begin{array}{l}\text { Gaya Kepemimpinan } \\
\text { (X1) }\end{array}$ & 222 & 18 & 75 & 62.46 & 10.633 \\
\hline Kompensasi (X2) & 222 & 19 & 75 & 67.09 & 8.454 \\
\hline Kepuasan Kerja (Y) & 222 & 18 & 75 & 68.21 & 7.936 \\
\hline Valid N (listwise) & 222 & & & & \\
\hline
\end{tabular}

Gaya Kepemimpinan diperoleh varians minimum sebesar 18 dan varians maximum 75 dengan mean score sebesar 6,24 dengan standar deviasi 10,633. Kompensasi diperoleh varians minimum sebesar 19 dan varians maximum 75 dengan mean score sebesar 6,70 dengan standar deviasi 8,454. Kepuasan Kerja diperoleh varians minimum 
sebesar 18 dan varians maximum 75 dengan mean score sebesar 6,82 dengan standar deviasi 7,936.

\section{Analisis Verifikatif.}

Pada analisis ini dimaksudkan untuk mengetahui pengaruh variabel independen terhadap variabel dependen. Adapun hasil pengujian sebagai berikut:

\section{a. Analisis Regresi Linier Berganda}

Uji regresi ini dimaksudkan untuk mengetahui perubahan variabel dependen jika variabel independen mengalami perubahan. Adapun hasil pengujiannya sebagai berikut:

\section{Tabel 2. Hasil Pengujian Regresi Liner Berganda}

\begin{tabular}{|c|c|c|c|c|c|c|}
\hline \multirow{3}{*}{\multicolumn{2}{|c|}{ Model }} & \multicolumn{2}{|c|}{ Coefficients $^{a}$} & \multirow{3}{*}{$\begin{array}{c}\text { Standardized } \\
\text { Coefficients } \\
\text { Beta }\end{array}$} & \multirow[b]{3}{*}{$\mathrm{t}$} & \multirow[b]{3}{*}{ Sig. } \\
\hline & & \multicolumn{2}{|c|}{$\begin{array}{l}\text { Unstandardized } \\
\text { Coefficients }\end{array}$} & & & \\
\hline & & $\mathrm{B}$ & Std. Error & & & \\
\hline & (Constant) & 16.318 & 2.354 & & 6.933 & .000 \\
\hline & $\begin{array}{l}\text { Gaya Kepemimpinan } \\
\text { (X1) }\end{array}$ & .287 & .036 & .384 & 8.041 & .000 \\
\hline & Kompensasi (X2) & .506 & .045 & .539 & 11.279 & .000 \\
\hline
\end{tabular}

a. Dependent Variable: Kepuasan Kerja (Y)

Berdasarkan hasil pengujian pada tabel di atas, diperoleh persamaan regresi $\mathrm{Y}=16,318+$ $0,287 \mathrm{X} 1+0,506 \mathrm{X} 2 . \quad$ Dari persamaan tersebut dijelaskan sebagai berikut:

a) Konstanta sebesar 16,318 diartikan jika Gaya Kepemimpinan dan Kompensasi tidak ada, maka telah terdapat nilai Kepuasan Kerja sebesar 16,318 point.

b) Koefisien regresi Gaya Kepemimpinan sebesar 0,287, angka ini positif artinya setiap ada peningkatan Gaya Kepemimpinan sebesar 0,287 maka Kepuasan Kerja juga akan mengalami peningkatan sebesar 0,287 point.

c) Koefisien regresi Kompensasi sebesar 0,506, angka ini positif artinya setiap ada peningkatan Kompensasi sebesar 0,506 maka Kepuasan Kerja juga akan mengalami peningkatan sebesar 0,506 point.

\section{b. Analisis Koefisien Korelasi}

Analisis koefisien korelasi dimaksudkan untuk mengetahui tingkat kekuatan hubungan dari variabel independen terhadap variabel dependen baik secara parsial maupun simultan. Adapun hasil pengujian sebagai berikut: 
Tabel 3. Hasil Pengujian Koefisien Korelasi Gaya Kepemimpinan Terhadap Kepuasan Kerja. Correlations

\begin{tabular}{llr|r} 
& & \multicolumn{1}{c}{$\begin{array}{c}\text { Gaya } \\
\text { Kepemimpina } \\
\text { n }\end{array}$} & \multicolumn{1}{c}{$\begin{array}{c}\text { Kepuasan } \\
\text { Kerja }\end{array}$} \\
\hline GayaKepemimpinan & Pearson Correlation & 1 & $.729^{* *}$ \\
\cline { 2 - 4 } & Sig. (2-tailed) & 222 & .000 \\
\cline { 2 - 4 } KepuasanKerja & $\mathrm{N}$ & $.729^{* *}$ & 222 \\
\cline { 2 - 4 } & Pearson Correlation & .000 & 1 \\
\cline { 2 - 4 } & Sig. (2-tailed) & 222 & 222 \\
\hline
\end{tabular}

**. Correlation is significant at the 0.01 level (2-tailed).

Berdasarkan hasil pengujian diperoleh nilai korelasi sebesar 0,729 artinya
Gaya Kepemimpinan memiliki hubungan yang kuat terhadap Kepuasan Kerja.

Tabel 4. Hasil Pengujian Koefisien Korelasi Kompensasi Terhadap Kepuasan Kerja Correlations

\begin{tabular}{llr|r} 
& & Kompensasi & Kepuasan Kerja \\
\hline Kompensasi & Pearson Correlation & 1 & $.785^{* *}$ \\
\cline { 2 - 4 } & Sig. (2-tailed) & 222 & .000 \\
\cline { 2 - 4 } KepuasanKerja & $\mathrm{N}$ & $.785^{* *}$ & 222 \\
\cline { 2 - 4 } & Pearson Correlation & .000 & 1 \\
\cline { 2 - 4 } & Sig. (2-tailed) & 222 & 222 \\
\cline { 2 - 4 } & $\mathrm{N}$ & & \\
\hline **. Correlation is significant at the 0.01 level (2-tailed).
\end{tabular}

Berdasarkan hasil pengujian diperoleh nilai korelasi sebesar 0,785 artinya Kompensasi memiliki hubungan yang kuat terhadap Kepuasan Kerja.

Tabel 5. Hasil Pengujian Koefisien Korelasi Gaya Kepemimpinan dan Kompensasi secara simultan Terhadap Kepuasan Kerja. Model Summary

\begin{tabular}{lr|r|r|rr} 
Model & R & R Square & Adjusted R Square & $\begin{array}{c}\text { Std. Error of the } \\
\text { Estimate }\end{array}$ \\
\hline 1 & $.839^{\mathrm{a}}$ & .704 & .701 & 4.338 \\
\hline
\end{tabular}

a. Predictors: (Constant), Kompensasi (X2), Gaya Kepemimpinan (X1)

b. Dependent Variable: Kepuasan Kerja (Y) 


Berdasarkan hasil
pengujian diperoleh nilai
korelasi sebesar 0,839 artinya
Gaya Kepemimpinan dan
Kompensasi secara simultan
memiliki hubungan yang kuat
terhadap Kepuasan Kerja.

c. Analisis

Determinasi

Tabel 6. Hasil Pengujian Koefisien Determinasi Gaya Kepemimpinan

\section{Terhadap Kepuasan Kerja Model Summary}

\begin{tabular}{lr|r|r|r} 
Model & R & R Square & Adjusted R Square & $\begin{array}{c}\text { Std. Error of the } \\
\text { Estimate }\end{array}$ \\
\hline 1 & $.729 \mathrm{a}$ & .532 & .530 & 5.442 \\
\hline
\end{tabular}

a. Predictors: (Constant), GayaKepemimpinan (X1)

\begin{tabular}{llr}
\multicolumn{2}{c}{ Berdasarkan } & hasil \\
pengujian & diperoleh & nilai \\
determinasi & sebesar & 0,532 \\
artinya Gaya & Kepemimpinan
\end{tabular}

Tabel 7. Hasil Pengujian Koefisien Determinasi Kompensasi Terhadap Kepuasan Kerja

Model Summary

\begin{tabular}{|c|c|c|c|c|}
\hline \multirow[b]{2}{*}{ Model } & \multicolumn{3}{|c|}{$\begin{array}{l}\text { Kepuasan Kerja } \\
\text { Model Summary }\end{array}$} & \multirow[b]{2}{*}{$\begin{array}{l}\text { Std. Error of the } \\
\text { Estimate }\end{array}$} \\
\hline & $\mathrm{R}$ & R Square & Adjusted R Square & \\
\hline 1 & $.785 a$ & .617 & .615 & 4.926 \\
\hline
\end{tabular}

memiliki kontribusi pengaruh sebesar 53,2\% terhadap Kepuasan Kerja. koefisien determinasi dimaksudkan untuk mengetahui besarnya persentase pengaruh dari variabel independen terhadap variabel dependen baik secara parsial maupun simultan. Adapun hasil pengujian sebagai berikut:

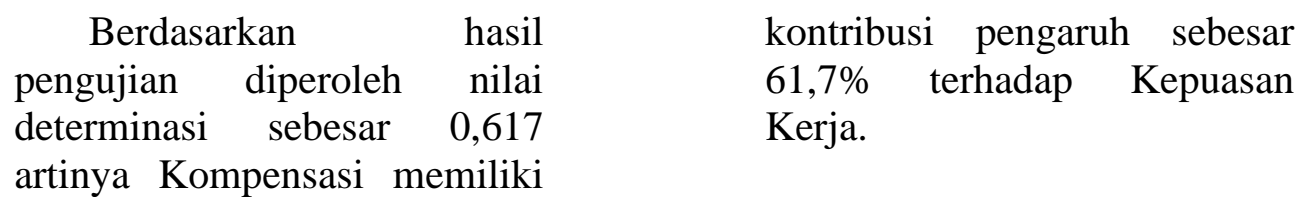

Tabel 8. Hasil Pengujian Koefisien Determinasi Gaya Kepemimpinan dan Kompensasi Terhadap Kepuasan Kerja Model Summary

\begin{tabular}{|c|c|c|c|c|c|}
\hline Model & $\mathrm{R}$ & R Square & Adjusted R Square & $\begin{array}{r}\text { Std. Error } \\
\text { Estima } \\
\end{array}$ & $\begin{array}{l}\text { of the } \\
\text { ite }\end{array}$ \\
\hline 1 & $.839 a$ & .704 & .701 & & 4.338 \\
\hline \multicolumn{6}{|c|}{$\begin{array}{l}\text { a. Predictors: (Constant), Kompensasi (X2), Gaya Kepemimpinan (X1) } \\
\text { b. Dependent Variable: Kepuasan Kerja (Y) }\end{array}$} \\
\hline \multicolumn{2}{|c|}{ Berdasarkan } & $\begin{array}{r}\text { hasil } \\
\text { nilai }\end{array}$ & $\begin{array}{l}\text { determinasi } \\
\text { artinya Gaya }\end{array}$ & $\begin{array}{l}\text { sebesar } \\
\text { Kepemil }\end{array}$ & $\begin{array}{r}0,704 \\
\text { mpinan }\end{array}$ \\
\hline
\end{tabular}


dan Kompensasi secara simultan memiliki kontribusi pengaruh sebesar 70,4\% terhadap Kepuasan Kerja, sedangkan sisanya sebesar $29,6 \%$ dipengaruhi faktor lain. d. Uji Hipotesis

Uji hipotesis Parsial (Uji t)

Pengujian hipotesis dengan uji $\mathrm{t}$ digunakan untuk mengetahui hipotesis parsial mana yang diterima.

Tabel 9. Hasil Uji Hipotesis Gaya Kepemimpinan Terhadap Kepuasan Kerja Coefficients $^{\mathrm{a}}$

\begin{tabular}{|c|c|c|c|c|c|}
\hline \multirow[b]{2}{*}{ Model } & \multicolumn{2}{|c|}{$\begin{array}{l}\text { Unstandardized } \\
\text { Coefficients }\end{array}$} & \multirow{2}{*}{$\begin{array}{c}\text { Standardized } \\
\text { Coefficients } \\
\text { Beta }\end{array}$} & \multirow[b]{2}{*}{$\mathrm{t}$} & \multirow[b]{2}{*}{ Sig. } \\
\hline & B & Std. Error & & & \\
\hline $1 \quad$ (Constant) & 34.208 & 2.181 & & 15.683 & .000 \\
\hline Kompensasi (X1) & .544 & .034 & .729 & 15.812 & .000 \\
\hline
\end{tabular}

a. Dependent Variable: KepuasanKerja

Berdasarkan hasil pengujian pada tabel di atas, diperoleh nilai thitung untuk variable Gaya Kepemimpinan 15.812 lebih besar dibandingkan dengan nilai ttabel 1.971, atau nilai sig. $\mathrm{t}$ untuk Variabel Gaya Kepemimpinan 0.000 lebih PT. Citra Rasa Betawi. kecil dari alpha 0.05 berdasarkan hasil yang diperoleh maka menolak $\mathrm{H}_{\mathrm{o}}$ dan menerima $\mathrm{Ha}$ untuk Variabel Gaya Kepemimpinan. Dengan demikian secara parsial Gaya Kepemimpinan berpengaruh posistif dan signifikan terhadap Kepuasan Kerja karyawan pada

Tabel 10. Hasil Uji Hipotesis Kompensasi Terhadap Kepuasan Kerja

Coefficients $^{\mathrm{a}}$

\begin{tabular}{|c|c|c|c|c|c|}
\hline \multirow[b]{2}{*}{ Model } & \multicolumn{2}{|c|}{$\begin{array}{l}\text { Unstandardized } \\
\text { Coefficients }\end{array}$} & \multirow{2}{*}{$\begin{array}{c}\text { Standardized } \\
\text { Coefficients } \\
\text { Beta } \\
\end{array}$} & \multirow[b]{2}{*}{$t$} & \multirow[b]{2}{*}{ Sig. } \\
\hline & $\mathrm{B}$ & Std. Error & & & \\
\hline $\begin{array}{ll}1 & \text { (Constant) }\end{array}$ & 18.762 & 2.650 & & 7.080 & .000 \\
\hline $\begin{array}{l}\text { Kepuasan Kerja } \\
\text { (X2) }\end{array}$ & .737 & .039 & .785 & 18.807 & .000 \\
\hline
\end{tabular}

a. Dependent Variable: KepuasanKerja

Berdasarkan hasil Berdasarkan hasil pengujian pada tabel di atas, diperoleh nilai thitung untuk Variable Kompenasai (X2) 18.807 lebih besar dibandingkan dengan nilai ttabel 1.971, atau nilai sig. t untuk Variabel Kompensasi
0.000 lebih kecil dari alpha 0.05

berdasarkan hasil yang diperoleh maka menolak $\mathrm{H}_{\mathrm{o}}$ dan menerima Ha untuk Variabel Kompensasi. Dengan demikian secara parsial Kompensasi berpengaruh posistif dan signifikan terhadap Kepuasan 
Kerja Karyawan pada PT. Citra Rasa Betawi.
Uji Hipotesis Simultan (Uji F)

Pengujian hipotesis dengan uji $F$ digunakan untuk mengetahui hipotesis simultan yang mana yang diterima.

\section{Tabel 11. Hasil Uji Hipotesis Gaya Kepemimpinan dan Kompensasi Terhadap Kepuasan Kerja.}

ANOVA $^{\mathrm{a}}$

\begin{tabular}{llr|r|r|c|c}
\multicolumn{1}{l}{ Model } & Sum of Squares & df & Mean Square & F & Sig. \\
\hline 1 & Regression & 9798.025 & 2 & 4899.012 & 260.344 & $.000 \mathrm{~b}$ \\
\cline { 2 - 7 } & Residual & 4121.025 & 219 & 18.817 & & \\
\hline & Total & 13919.050 & 221 & & & \\
\hline
\end{tabular}

a. Dependent Variable: KepuasanKerja

b. Predictors: (Constant), Kompensasi, GayaKepemimpinan

Berdasarkan hasil pengujian pada tabel di atas, diperoleh nilai Fhitung 260.344 lebih besar dibandingkan dengan Ftabel 3.04, dan Sig. 0,000 lebih kecil dari alpha 5\% (0.05). artinya secara berssmasama variable bebas yang terdiri dari variable Gaya Kepemimpinan (X1) dan variable Kompensasi (X2) berpengaruh posistif dan signifikan terhadap variable Kepuasan Kerja Karyawan (Y).

\section{PEMBAHASAN \\ PENELITIAN}

HASIL

1. Pengaruh Secara Parsial antara Gaya Kepemimpinan (X1) terhadap Kepuasan Kerja Karyawan (Y).

Terdapat pengaruh posistif dan signifikan secara parsial antara Gaya Kepemimpinan (X1) terhadap Kepuasan Kerja Karyawan (Y). hal ini ditunjukan dengan nilai thitung Variabel Gaya Kepemimpinan (X1) terhadap Kepuasan Kerja Karyawan (Y) sebesar thitung $15.812>$ ttabel
1.971. atau Sig $0.000<0.05$ Maka Ho ditolak dan Ha diterima artinya terdapat pengaruh yang positif dan signifikan antara Gaya Kepemimpinan (X1) terhadap Kepuasan Kerja Karyawan (Y).

2. Pengaruh Secara Parsial antara Kompensasi (X2) terhadap Kepuasan Kerja Karyawan (Y).

Terdapat pengaruh positif dan signifikan secara parsial antara Kompensasi (X2) terhadap Kepuasan Kerja Karyawan (Y). hal ini ditunjukan dengan nilai thitung Variabel Kompensasi (X2) terhadap Kepuasan Kerja Karyawan (Y) sebesar thitung $18.807>$ ttabel 1.971. atau Sig $0.000<0.05$ Maka Ho ditolak dan $\mathrm{Ha}$ diterima artinya terdapat pengaruh yang signifikan antara Kompensasi terhadap Kepuasan Kerja Karyawan.

3. Pengaruh Secara Simultan antara Gaya Kepemimpinan (X1), Kompensasi (X2) terhadap Kepuasan Kerja Karyawan (Y).

Terdapat pengaruh positif dan signifikan secara simultan antara Gaya Kepemimpinan (X1), 
Kompensasi (X2) terhadap Kepuasan Kerja Karyawan (Y). hal ini ditunjukan dengan nilai Fhitung 260.344 lebih besar dibandingkan dengan Ftabel 3.04, dan Sig. 0,000 lebih kecil dari alpha $5 \% \quad(0.05)$. hal ini mengindikasikan bahwa hasil penelitian menolak Ho dan menerima $\mathrm{Ha}$ dengan demikian secara serempak Gaya Kepemimpinan dan Kompensasi berpengaruh signifikan terhadap Kepuasan Kerja Karyawan pada PT. Citra Rasa Betawi.

\section{KESIMPULAN DAN SARAN}

\section{A. Kesimpulan}

1. Gaya Kepemimpinan berpengaruh positif dan signifikan terhadap Kepuasan kerja dengan kontribusi pengaruh sebesar 53.2\% Uji hipotesis diperoleh thitung $15.812>$ tabel 1.971. atau Sig $0.000<0.05$.

2. Kompensasi berpengaruh signifikan terhadap Kepuasan Kerja dengan kontribusi pengaruh sebesar $61.7 \%$, Uji hipotesis diperoleh nilai thitung $18.807>$ tabel 1.971. atau Sig $0.000<0.05$.

3. Gaya Kepemimpinan dan Kompensasi berpengaruh signifikan terhadap Kepuasan Kerja dengan kontribusi pengaruh sebesar sebesar $70,4 \%$ sedangkan sisanya sebesar 29,6\% dipengaruhi faktor lain. Uji hipotesis diperoleh nilai Fhitung 260.344 lebih besar dibandingkan dengan Ftabel 3.04, dan Sig. 0,000 lebih kecil dari alpha 5\% (0.05).

\section{B. Saran}

1. Bagi perusahaan agar para pemimpin di perusahaan dapat mengambil keputusan yang bijaksana untuk kebaikan karyawan dan perusahaan, kemudian saran selanjutnya agar para pemimpin di perusahaan lebih sabar dan mampu mengtendalikan emosinya dalam menghadapi permasalahan yang sulit ataupun ketika ada karyawan yang melakukan kesalahan dalam bekerja, untuk dapat meningkatkan kepuasan kerja karyawan.

2. Bagi perusahaan agar perusahaan dapat memberikan program insentif kepada karyawan, memberikan tunjangan transport dan juga mengadakan fasilitas tambahan dengan pihak eksternal untuk kepentingan pinjaman uang, kredit motor/mobil/rumah untuk dapat meningkatkan kepuasan kerja karyawan.

3. Bagi perusahaan agar karyawan senior di perusahaan dapat memberikan arahan dan bimbingan bagi karyawan baru, kemudian saran selanjutnya bagi perusahaan adalah perusahaan harus menciptakan system promosi yang objektif dan kesempatan promosi yang terbukan untuk semua karyawan.

\section{DAFTAR PUSTAKA}

Afin Murtie, 2012. Menciptakan SDM Berkuwalitas,. PT. Gelora 
Aksara Pratama. Jakarta

Akbar, I. R. (2020). Pengaruh Kompensasi Dan Etos Kerja Terhadap Komitmen Organisasi Pada PT. Central Buana Mandiri. Value: Jurnal Manajemen dan Akuntansi, 15(1), 73-80.

Algifari. 2013. Statistika Induktif: untuk Ekonomi dan Bisnis. Yogyakarta:

Dessler. 2010. Manajemen Sumber Daya Manusia. Jakarta. Indeks.

Edy Sutrisno, 2009, "Manajemen Sumber Daya Manusia”, Jakarta, Kencana Pernada Media Group

Edy, Sutrisno, (2016), Manajemen Sumber Daya Manusia, Kencana Prenada Media Group, Jakarta.

Ghozali, Imam, (2016), Aplikasi Analis Multivariate Dengan Program IBM SPSS 21, Edisi 2, Universitas Diponegoro, Semarang.

Handoko, T. Hani. 2012, "Manajemen Personalia dan Sumber Daya Manusia".Yogyakarta:BPFE

Hasibuan, Malayu S.P, (2016), Manajemen Sumber Daya Manusia. Bumi Aksara, Jakarta.

Husein Umar, 2004, Metode Penelitian Untuk Skripsi Dan Tesis Bisnis, Cet ke 6, Jakarta : PT RajaGrafindo Persada.

Kadarisman. 2012. Manajemen Kompensasi. Jakarta: PT Raja Grafindo Persada.

Kartono, Kartini. Pemimpin dan Kepemimpinan. Jakarta: PT Raja Grafindo Persada, 2011.
Mangkunegara Anwar Prabu, 2014,Manajemen Sumber Daya Manusia Perusahaan, PT. Remaja Rosdakarya, Bandung.

Mangkunegara, Anwar Prabu. 2014. "Evaluasi Kinerja SDM". Bandung: Penerbit Refika Aditama.

Riduwan. 2014. Metode \& Teknik Penyusunan Proposal Penelitian. Bandung: Alfabeta.

Rivai, Veithzal dan Ella Djauhari Sagala. (2013), Manajemen Sumbert Daya Manusia Untuk Perusahaan, Rajawali Pers, Jakarta.

Sekolah Tinggi Ilmu Manajemen YKPN

Sugiyono, (2015), Metode Penelitian Kuantitatif, Kualitatif, dan $R \& D$, Cetakan Ke-22 Bandung: Alfabeta.

Sugiyono, 2013, Metode Penelitian Bisnis, Alfabeta,Bandung.

Sugiyono. 2011. "Metode Penelitian Kuantitatif, kualitatif dan $R$ \& $D$ ". Bandung: Alfabeta.

Sunarsi, D. (2018). Buku Ajar: Seminar Perencanaan Sumber Daya Manusia. Tangerang Selatan: Asmoro Mediatama

Sunarsi, D. (2018). Pengembangan Sumber Daya Manusia Strategik \& Karakterisrik Sistem Pendukungnya : Sebuah Tinjauan. Jurnal Ilmiah MEA (Manajemen, Ekonomi, \& Akuntansi), 2(3), $178-194$.

Sunarsi, D. (2019). Seminar Sumber Daya Manusia. Tangerang Selatan: Unpam Press. 